\title{
FACTORS THAT MAY PREVENT TRANSFER OF ANTI- BIOTIC RESISTANCE BETWEEN GRAM-NEGATIVE BACTERIA IN THE GUT
}

\author{
J. D. ANDERSON* \\ Department of Bacteriology, The Medical School, University Walk, Bristol 8
}

JAPANESE workers first noted that transfer of multiple drug resistance between members of Enterobacteriaceae did not take place as readily in the intestinal tract as in the laboratory (Akiba et al., 1961). Subsequent literature suggests that R-factor transfer rarely occurs in the human gut except during chemotherapy. Smith (1969) obtained evidence in a few instances of transfer of resistance from ingested $\mathrm{R}$-factor bearing organisms to a resident recipient in a single individual in the absence of antibiotics. Wiedemann, Knothe and Döll (1970), on the other hand, failed to detect transfer in three healthy persons from ingested resistant organisms to the resident bowel flora. In the study of Anderson, Gillespie and Richmond (1973), R-factor transfer did not occur in the absence of chemotherapy in four subjects who had ingested very large numbers of potential donor and recipient organisms even though the plasmids concerned could be freely transferred in a broth medium.

In the present investigation, possible reasons for the almost complete inhibition of R-factor transfer in the gut in the absence of chemotherapy have been studied in the laboratory with the plasmids that had been used in the human experiments (Anderson et al., 1973).

\section{MATERIALS AND METHODS}

Media

MacConkey bile-lactose agar was prepared with and without antibiotics as already described (Anderson et al., 1973). Media containing ampicillin, nalidixic acid, ampicillin with nalidixic acid, tetracycline, or tetracycline with nalidixic acid, were used for these studies. Brain-heart Infusion Broth was prepared from a dehydrated base (Difco, Bacto). Cysteine-serum broth was prepared as described by Hofstad and Kristoffersen, 1971. Cultures of Bacteroides fragilis were maintained by weekly subculture on Oxoid DST Agar supplemented with saponin-lysed oxalated horse blood $(5 \%)$.

Transfer experiments were usually performed in nutrient broth prepared from Difco Nutrient Broth base $(1.6 \%)$ and sodium chloride $(0.5 \%)$. Nutrient broth was also prepared containing sodium taurocholate $(0.8 \%, \mathrm{w} / \mathrm{v})$ or sodium glycocholate $(0.8 \%, \mathrm{w} / \mathrm{v})$. A slurry of cellulose powder (Whatman, chromatographic grade, $4 \cdot 1 \%$, w/v) in sterile nutrient broth was heated to $100^{\circ}$ for $30 \mathrm{~min}$. and then cooled immediately before use to destroy any bacteria present. Slurries of formalin-killed Escherichia coli, B. fragilis, and suspensions of various living organisms in nutrient broth were prepared as described below.

Received 26 Mar. 1974; accepted 31 May 1974.

* Present address: Group Pathology Laboratories, County Hospital, York YO3 7PG

J. MED. MICROBIOL.-VOL. 8 (1975) 


\section{Organisms and $R$ factors}

Two F-like $\mathrm{fi}^{+}$repressed $\mathrm{R}$ factors were used in this work (see Anderson et al., 1973). One (R-1), conferred resistance to ampicillin, chloramphenicol, kanamycin, streptomycin and sulphonamides; the other (R-222-1), determined resistance to chloramphenicol, streptomycin, sulphonamides, and tetracyclines.

A nalidixic-acid-resistant laboratory strain of $E$. coli (NAR) was used as a recipient for $\mathrm{R}$ factors.

The experimental $\mathbf{R}$ factors were introduced from a donor organism of different colonial appearance into each of two strains of $E$. coli that had been isolated from human faeces (Anderson et al., 1973). The new resistant strains derived from faecal organisms were then isolated and purified on media containing appropriate antibiotics.

Two strains of $B$. fragilis from human faeces were identified by biochemical reactions and antibiotic-disk-sensitivity tests, and grown by means of anaerobic-culture techniques that have already been described (Anderson and Sykes, 1973).

An isolate of Streptococcus faecalis was obtained from infected urine, and isolates of Staphylococcus albus and Neisseria catarrhalis from sputum: all these organisms were identified (Cowan and Steele, 1965) after purification and grown in bulk in cysteine-serum broth or brain-heart infusion broth.

\section{Factors affecting $R$-factor transfer}

Presence of B. fragilis. Stationary-phase cultures of one or other of the two strains of $B$. fragilis in cysteine-serum broth were centrifuged, and the precipitated bacteria resuspended in nutrient broth to provide suspensions containing suitable densities of viable cells. Overnight cultures of donor strains of $E$. coli containing plasmids R-1, or R-222-1, and of the recipient $E$. coli NAR, were each diluted 1 in 10 with fresh, warmed $\left(37^{\circ} \mathrm{C}\right)$ broth immediately before use.

In each experiment a mixture of diluted suspension of donor organism $(2 \mathrm{ml})$, diluted suspension of recipient organism $(2 \mathrm{ml})$ and prewarmed $\left(37^{\circ} \mathrm{C}\right)$ dense suspension $(6 \mathrm{ml})$ of one of the strains of $B$. fragilis was incubated at $37^{\circ} \mathrm{C}$ in screw-capped bottles $(30 \mathrm{ml})$. Viable counts of donor and recipient organisms, and of organisms resulting from plasmid transfer, were quantitatively determined (Miles, Misra and Irwin, 1938) on a suitable range of antibiotic-containing media. Counts were made at the start of the experiment, and again at $4 \mathrm{~h}$ and in some cases at $24 \mathrm{~h}$. Transfer frequency was expressed as the number of conjugants per donor organism after incubation for $4 \mathrm{~h}$.

Supernate from cultures of $B$. fragilis. Supernatant fluid was obtained by centrifugation of 40 -h stationary-phase cultures of $B$. fragilis in cysteine-serum broth. Organisms remaining in this fluid were removed by filtration through a Sartorius $0.45 \mu \mathrm{m}$ membrane filter (Sartorius, 34 Göttingen, West Germany). In each experiment, the diluted suspension of donor organism in nutrient broth $(2 \mathrm{ml})$, prepared as already described, was mixed with the diluted suspension of the recipient organism $(2 \mathrm{ml})$ and the filtered culture supernatant $(6 \mathrm{ml})$. Fresh cysteine-serum broth $(6 \mathrm{ml})$ was used as a control. Experiments were otherwise similar to those used to study the effect of $B$. fragilis upon transfer rates.

Supernates from more concentrated suspensions of $B$. fragilis were prepared by incubating saline-washed suspensions (c. $2 \times 10^{10}$ viable organisms per $\mathrm{ml}$ ) in nutrient broth at $37^{\circ} \mathrm{C}$ for $2 \mathrm{~h}$. The supernate was obtained from this suspension as described above.

Killed B. fragilis or $E$. coli. Stationary-phase $(40 \mathrm{~h})$ cultures of $B$. fragilis in cysteineserum broth (or 18-h cultures of $E$. coli in nutrient broth) were concentrated by centrifugation and resuspended in about $10 \%$ of their original volume of formol-saline $(2 \% \mathrm{v} / \mathrm{v})$ for $20 \mathrm{~min}$. The killed organisms were concentrated again by centrifugation, washed twice with fresh saline to remove residual formaldehyde, and finally resuspended in a suitable volume of nutrient broth. Rates of $\mathrm{R}$-factor transfer were studied by methods already described for analogous experiments with suspensions of viable $B$. fragilis.

Bile salts and cellulose-powder slurry. The method was similar to that already described for experiments with viable cultures of $B$. fragilis. Diluted suspensions of donor $(2 \mathrm{ml})$ and 
recipient $(2 \mathrm{ml})$ organisms in nutrient broth were added to $6-\mathrm{ml}$ volumes of nutrient broth containing either cellulose powder, sodium taurocholate, or sodium glycocholate to give the final concentrations of these substances shown in the table.

Living Strep. faecalis, Staph. albus, and N. catarrhalis. Overnight broth cultures of each of these organisms were concentrated by centrifugation and resuspended by stirring well during slow addition of nutrient broth. The effect of these organisms upon rates of conjugation was determined in experiments similar to those with $B$. fragilis.

Anaerobic conditions. Hydrogen was bubbled through cysteine-serum broth $(500 \mathrm{ml})$ contained in screw-capped bottles $(540 \mathrm{ml})$ to remove air. Overnight broth cultures $(9 \mathrm{ml})$ of donor and recipient organisms were added to each bottle; the bottles were filled to the top with fresh oxygen-free medium and the cultures mixed by rotating the bottles. Viable counts were determined at intervals as in similar experiments with $B$. fragilis. After each sample had been removed, the bottles were filled to the top with fresh medium to displace air. Portions $(20 \mathrm{ml})$ of the same donor-recipient-broth mixture in cotton-plugged conical flasks $(250 \mathrm{ml})$ served as " aerobic" controls.

\section{RESULTS AND DISCUSSION}

The aerobic Gram-negative bacteria that are known to be involved in $\mathrm{R}$-factor transfer form only a small minority of the intestinal flora, which is predominantly anaerobic (see Drasar, Shiner and McLeod, 1969; Gall, 1970). Since Bacteroides spp. form the main component of the gut flora, the effect of these organisms upon R-factor transfer was studied. Populations of donor and recipient organisms were chosen that were similar to those that might be found in faeces. The addition of suspension of $B$. fragilis of somewhat lower density than those normally found in faeces completely stopped $\mathbf{R}$-factor transfer (no detectable transfer even after $24 \mathrm{~h}$ ), whilst the addition even of quite small numbers of this organism had some effect (the table). Filtrates of $B$. fragilis cultures, or dense suspensions of formalin-killed organisms had relatively little effect on transfer (the table). The effect of $B$. fragilis may be due to the production of an unstable metabolite, or to a component that is destroyed by formalin, which either specifically inhibits conjugation or suppresses metabolism.

The effect of dense suspensions of $E$. coli, or a slurry of cellulose powder upon transfer frequencies (the table) suggests that inhibition of conjugation in the gut is unlikely to be due entirely to the purely mechanical effects of inert material.

Conjugation is known to be inhibited in broth cultures by bile salts such as sodium taurocholate (Koyama and Akiba, 1961; Wiedemann, 1972). These may act by lowering surface tension, because sodium dodecyl sulphate, an anionic detergent, has a similar effect (Yokota and Akiba, 1961), although other authors (Chaloupecky and Zahradnik, 1972) found that compounds lowering surface tension did not influence transmission in vitro. The effect of bile salts and bile pigments upon R-factor transfer in the gut is difficult to assess in the laboratory, because bile salts undergo a variety of chemical changes during passage down the gut. A realistic laboratory model for bile salt or bile pigment action cannot therefore be provided and laboratory findings should be viewed with some reservation. Nevertheless bile salts do have some inhibitory effect upon conjugation in vitro (the table), and may do so in vivo. 
Wiedemann (1972) found that Strep. faecalis inhibited R-factor transfer. Although this effect was confirmed here, it was not marked even with much higher concentrations of this organism than are normally found in faeces.

\section{TABLE}

Laboratory studies of factors that may explain the low frequency of $R$-factor transfer in the human gut*

\begin{tabular}{|c|c|c|}
\hline \multirow{2}{*}{ Factor tested } & \multicolumn{2}{|c|}{ Mean transfer frequency $\dagger$ of } \\
\hline & donor plasmid R-1 & donor plasmid R-222-1 \\
\hline Nutrient broth control & $\begin{array}{c}6.0 \times 10^{-3} \\
\left(32 ; 2 \cdot 4 \rightarrow 12 \times 10^{-3}\right)\end{array}$ & $\begin{array}{c}7 \cdot 6 \times 10^{-3} \\
\left(32 ; 2 \cdot 0 \rightarrow 12 \cdot 2 \times 10^{-3}\right.\end{array}$ \\
\hline Nutrient broth containing $c .2 \times 10^{10}$ & $<10^{-8}$ & $<10^{-8}$ \\
\hline
\end{tabular}
Bacteroides fragilis per $\mathrm{ml}$

(8; no detectable transfer) $(8 ;$ no detectable transfer $)$

Nutrient broth containing 3-5 $\times 10^{9}$ B. fragilis per $\mathrm{ml}$

Nutrient broth containing $c .2 \times 10^{10}$ formalin-killed $B$. fragilis

Supernate from nutrient broth that had been incubated for $2 \mathrm{~h}$ with $c .2 \times 10^{10}$ $B$. fragilis

$$
\begin{gathered}
3 \cdot 2 \times 10^{-3} \\
\left(6 ; 0 \cdot 2 \rightarrow 3 \cdot 8 \times 10^{-3}\right) \\
4 \cdot 4 \times 10^{-3} \\
\left(4 ; 2 \cdot 2 \rightarrow 8 \cdot 0 \times 10^{-3}\right) \\
4 \cdot 0 \times 10^{-3}
\end{gathered}
$$

(1)

$2.6 \times 10^{-3}$

(1) culture of $B$. fragilis in cysteine-serum broth

Nutrient broth containing c. $2 \times 1011$ formolised Escherichia coli per ml

Nutrient broth containing a suspension of cellulose powder $2.5 \%(\mathrm{w} / \mathrm{v})$

Nutrient broth containing sodium taurocholate $0.5 \%(\mathrm{w} / \mathrm{v})$

Nutrient broth containing sodium glycocholate $0.5 \%(w / v)$

Nutrient broth containing c. $2 \times 10^{9}$ Streptococcus faecalis per $\mathrm{ml}$

Nutrient broth containing c. $1 \times 10^{10}$ Staphylococcus albus per $\mathrm{ml}$

Nutrient broth containing c. $1 \times 10^{10}$ Neisseria catarrhalis per ml

Cysteine-serum broth incubated aerobically

Cysteine-serum broth incubated anaerobically

\section{$5.4 \times 10^{-3}$}

$\left(4 ; 4.0 \rightarrow 6.4 \times 10^{-3}\right)$

$6.8 \times 10^{-3}$

(1)

$3.6 \times 10^{-3}$

$\left(4 ; 2 \cdot 0 \rightarrow 5 \cdot 8 \times 10^{-3}\right)$

$5.5 \times 10^{-3}$

(1)

$2.9 \times 10^{-3}$

$\left(3 ; 1.9 \rightarrow 4.2 \times 10^{-3}\right)$

$1.9 \times 10^{-3}$

(1)

$7 \cdot 3 \times 10^{-3}$

(1)

$1.2 \times 10^{-2}$

$\left(3 ; 0.8 \rightarrow 1.7 \times 10^{-2}\right)$

$1.2 \times 10^{-2}$

$\left(3 ; 0.9 \rightarrow 1.7 \times 10^{-2}\right)$

$$
\begin{gathered}
3.0 \times 10^{-3} \\
\left(6 ; 0.6 \rightarrow 4.0 \times 10^{-3}\right) \\
4.6 \times 10^{-3} \\
\left(4 ; 2.0 \rightarrow 7.0 \times 10^{-3}\right)
\end{gathered}
$$

$4.8 \times 10^{-3}$

(1)

$4 \cdot 2 \times 10^{-3}$

(1)

$5.6 \times 10^{-3}$

$\left(4 ; 3 \cdot 0 \rightarrow 7 \cdot 2 \times 10^{-3}\right)$

$7 \cdot 9 \times 10^{-3}$

(1)

$1.7 \times 10^{-3}$

$\left(4 ; 1.1 \rightarrow 2.6 \times 10^{-3}\right)$

$3.2 \times 10^{-3}$

(1)

$3.1 \times 10^{-3}$

(3; $2 \cdot 0 \rightarrow 5 \cdot 6 \times 10^{-3}$ )

$3.2 \times 10^{-3}$

$7 \cdot 8 \times 10^{-3}$

(1)

$1.5 \times 10^{-2}$

$\left(3 ; 1.0 \rightarrow 2 \cdot 2 \times 10^{-2}\right)$

$1.6 \times 10^{-2}$

$\left(3 ; 0.8 \rightarrow 2.6 \times 10^{-2}\right)$

* See text for details of $\mathbf{R}$ factors, organisms, and experimental technique.

$\dagger$ Defined in Methods section; figures in brackets show the number of individual determinations and the observed range of values. 
Similarly Staph. albus and $N$. catarrhalis, which are not normally found in large numbers in the gut, had little effect upon conjugation.

The partial pressure of oxygen in human intestinal gas is low (Askevold, 1956) and the predominant flora is strictly anaerobic. Nevertheless, transfer rates of both $\mathrm{R}$ factors used in this study were found to be the same under both aerobic and anaerobic conditions. Although Stallions and Curtiss (1972) obtained similar findings, other workers (Fisher, 1957a; Egawa et al., 1961; Moodie and Woods, 1973) have found that anaerobiosis may inhibit conjugation under certain conditions. It is not certain, therefore, that anaerobic conditions do not inhibit R-factor transfer in the gut.

Growth of $E$. coli in mixed culture was almost completely prevented by dense suspensions of $B$. fragilis and, as has been suggested, suppression of metabolism in $E$. coli under such conditions provides a possible explanation for the inhibition of conjugation. This view is confirmed by experimental studies, which have indicated that energy provided by oxidative phosphorylation is probably essential for R-factor transfer (Fisher, 1957a and $b$; Egawa et al., 1961). The other factors studied, which had a less marked effect upon conjugation, depressed growth rates to as little as $10 \%$ of that of the controls.

The presence of dense cultures of $\boldsymbol{B}$. fragilis thus provides a satisfactory explanation for the inhibition of conjugation in the human gastro-intestinal tract in the absence of antibiotics. Other factors that inhibit conjugation to a lesser degree may reinforce the effects of $B$. fragilis. Other gut anaerobes such as Veillonella spp. and Gram-positive cocci, which are also very numerous, may well have a similar effect to $B$. fragilis, and there is obviously a need for further studies in this field.

Therapeutic courses of ampicillin or tetracycline increased populations of resistant organisms, arising in the gut by conjugation, from undetectable to very large numbers (Anderson et al., 1973). It is possible that as well as selecting for resistant organisms, antibiotics may also act indirectly by interfering with the Gram-positive or Gram-negative anaerobic flora which may normally suppress R-factor transfer.

\section{SUMMARY}

Antibiotic-resistance transfer between populations of donor and recipient strains of Escherichia coli was completely inhibited in broth by dense suspensions of Bacteroides fragilis. Comparable amounts of inert bacterial matter (formolised suspensions of $E$. coli or $B$. fragilis), or smaller numbers of viable B. fragilis, Streptococcus faecalis, Staphylococcus albus, Neisseria catarrhalis, or solutions of sodium taurocholate or glycocholate were only moderately inhibitory. Anaerobiosis had no effect upon plasmid transfer. Population densities of enteric organisms in these studies were similar to those found in faeces. The presence of dense cultures of $B$. fragilis provide a satisfactory explanation for the almost total inhbition of conjugation in the human gut. Other factors inhibiting conjugation to a lesser degree may reinforce the effect of $B$. fragilis in vivo.

As well as selecting for resistant organisms, antibiotics may also indirectly 
increase populations of R-factor-bearing organisms in the gut by interfering with the anaerobic flora and so permit an increase in the frequency of conjugation.

I am very grateful to Professor W. A. Gillespie for his interest and to Miss M. A. C. Jones for technical help. M. A. C. J. was supported by a Programme Grant to Professor M. H. Richmond from the Medical Research Council.

\section{REFERENCES}

Akiba, T., Koyama, K., Kimura, S. and Fukushima, T. 1961. Quoted by Watanabe, T. 1963. Infective heredity of multiple drug resistance in bacteria. Bact. Rev., 27, 87.

Anderson, J. D., Gillespie, W. A. AND Richmond, M. H. 1973. Chemotherapy and antibiotic-resistance transfer between enterobacteria in the human gastro-intestinal tract. J. med. Microbiol., 6, 461.

ANDERSON, J. D. AND SYKes, R. B. 1973. Characterisation of a $\beta$-lactamase obtained from a strain of Bacteroides fragilis resistant to $\beta$-lactam antibiotics. J. med. Microbiol., 6, 201.

AskEVOLD, F. 1956. Investigations on the influence of diet on the quantity and composition of intestinal gas in humans. Scand. J. clin. Lab. Invest., 8, 87.

Chaloupecky, V. AND ZAHRADNIK, F. 1972. Die R Faktorenübertragung bei verminderter Oberflächenspannung. Zentbl Bakt. ParasitKde, 1, Abt. Orig., A219, 348.

Cowan, S. T. AND Steele, K. J. 1965. Manual for the identification of medical bacteria, London.

Drasar, B. S., Shiner, M. ANd Mcleod, G. M. 1969. Studies on the intestinal flora. 1. The bacterial flora of the gastro-intestinal tract in healthy and achlorhydric persons. Gastroenterology, 56, 71.

Egawa, R., Hashimoto, H., Honda, T., Mitsuhasi, S., Harada, K., Kameda, M. and SuzukI, M. 1961. Quoted by WaTANABE, T. 1963. Infective heredity of multiple drug resistance in bacteria. Bact. Rev., 27, 87.

Fisher, K. W. 1957a. The role of the Krebs cycle in conjugation in Escherichia coli K-12. J. gen. Microbiol., 16, 120.

FISHER, K. W. 1957b. The nature of the endergonic processes in conjugation in Escherichia coli K-12. J. gen. Microbiol., 16, 136.

GaLl, L. S. 1970. Normal faecal flora of man. Am. J. clin. Nutr., 23, 1457.

HOFSTAD, T. AND KRISTOFFERSEN, T. 1971. Lipopolysaccharide from Bacteroides melaninogenicus isolated from the supernatant fluid after ultracentrifugation of the water phase following phenol-water extraction. Acta path. microbiol. scand., B79, 12.

Koyama, K. AND AKIBA, T. 1961. Quoted by Watanabe, T. 1963. Infective heredity of multiple drug resistance in bacteria. Bact. Rev., 27, 87.

Miles, A. A., MisRa, S. S. AND IRwIN, J. O. 1938. The estimation of the bactericidal power of the blood. J. Hyg., Camb., 38, 732.

Moodie, H. L. AND Woods, D. R. 1973. Anaerobic R factor transfer in Escherichia coli. J. gen. Microbiol., 76, 437.

SMITH, H. W. 1969. Transfer of antibiotic resistance from animal and human strains of Escherichia coli to resident $E$. coli in the alimentary tract of man. Lancet, 1, 1174.

Stallions, D. R. AND CuRTiss, R. III. 1972. Bacterial conjugation under anaerobic conditions. J. Bact., 111, 294.

Wiedemann, B., KNothe, H. AND Döll, E. 1970. Übertragung von R-Faktoren in der Darmflora des Menschen. Zentbl Bakt. ParasitKde, 1 Abt. Orig., 213, 183.

WIEDEMANN, B. 1972. Resistance transfer in vivo and its inhibition. In Bacterial plasmids and antibiotic resistance, edited by V. Krcméry, L. Rosival, and T. Watanabe, Berlin, p. 75 .

Yokota, T. AND Akiba, T. 1961. Quoted by Watanabe, T. 1963. Infective heredity of multiple drug resistance in bacteria. Bact. Rev., 27, 87. 